\title{
Assessment of Lithium-based Battery Electrolytes Developed under the NASA PERS Program
}

\author{
William R. Bennett \\ QSS Group, Inc. \\ and \\ Richard S. Baldwin \\ NASA Glenn Research Center
}

\begin{abstract}
Recently, NASA formally completed the Polymer Energy Rechargeable System (PERS) Program, which was established in 2000 in collaboration with the Air Force Research Laboratory (AFRL) to support the development of polymer-based, lithium-based cell chemistries and battery technologies to address the next generation of aerospace applications and mission needs. The goal of this program was to ultimately develop an advanced, space-qualified battery technology, which embodied a solid polymer electrolyte (SPE) and complementary components, with improved performance characteristics that would address future aerospace battery requirements.
\end{abstract}

Programmatically, the PERS initiative exploited both interagency collaborations to address common technology and engineering issues and the active participation of academia and private industry. The initial program phases focused on R\&D activities to address the critical technical issues and challenges at the cell level. A variety of cell and polymeric electrolyte concepts were pursued as part of the development efforts undertaken at numerous governmental, industrial and academic laboratories. Numerous candidate electrolyte materials were developed, synthesized and optimized for evaluation. Utilizing the component screening facility and the "standardized" test procedures developed at the NASA Glenn Research Center, electrochemical screening and performance evaluations of promising candidate materials were completed.

This overview summarizes test results for a variety of candidate electrolyte materials that were developed under the PERS Program. Electrolyte properties are contrasted and compared to the original project goals, and the strengths and weaknesses of the electrolyte chemistries are discussed. Limited cycling data for full-cells using lithium metal and vanadium oxide electrodes are also presented. Based on measured electrolyte properties, the projected performance characteristics and temperature limitations of batteries utilizing the advanced electrolytes and components have been estimated. Limitations for the achievement of practical performance levels are also discussed, as well as needs for future research and development. 

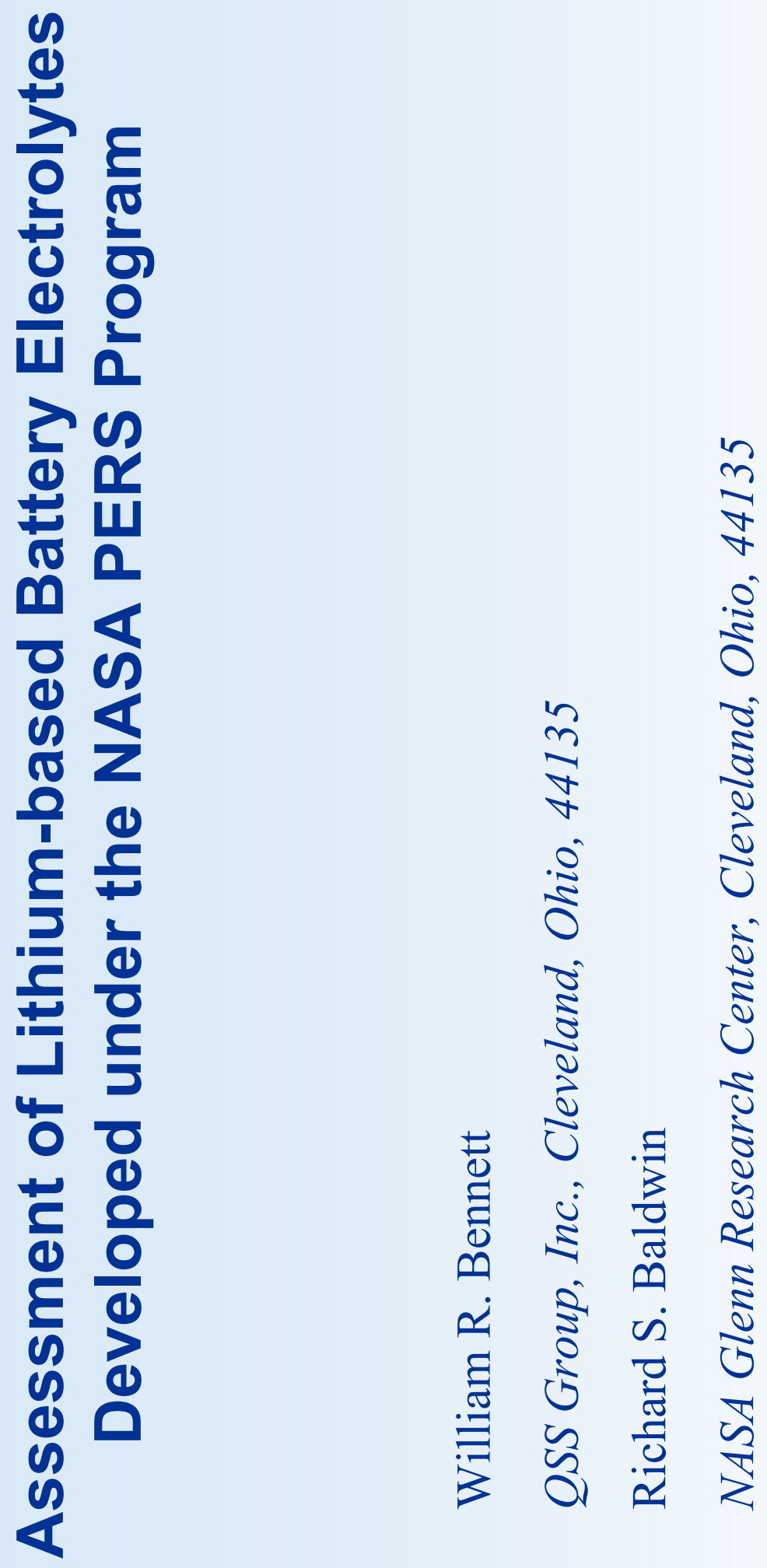


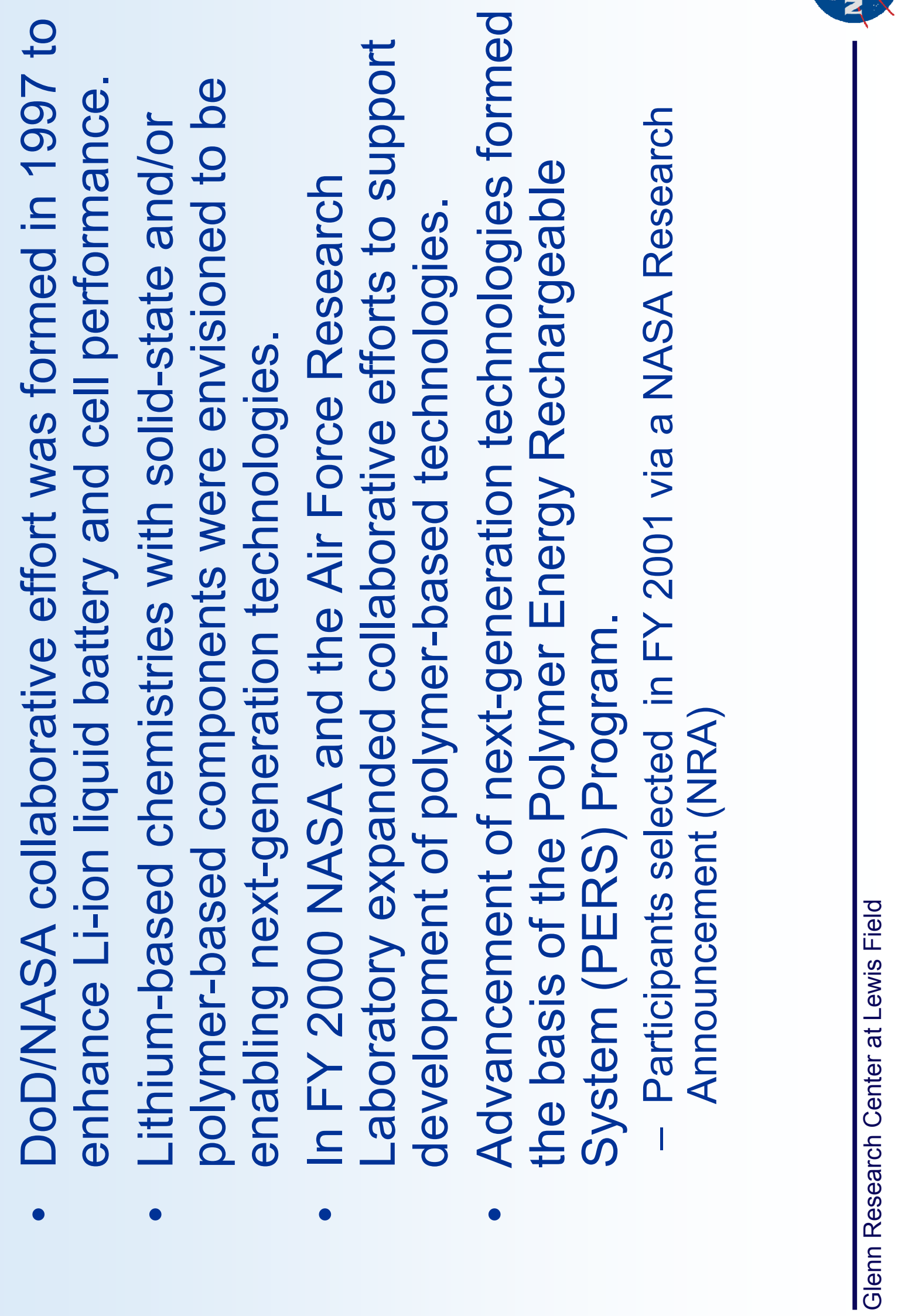



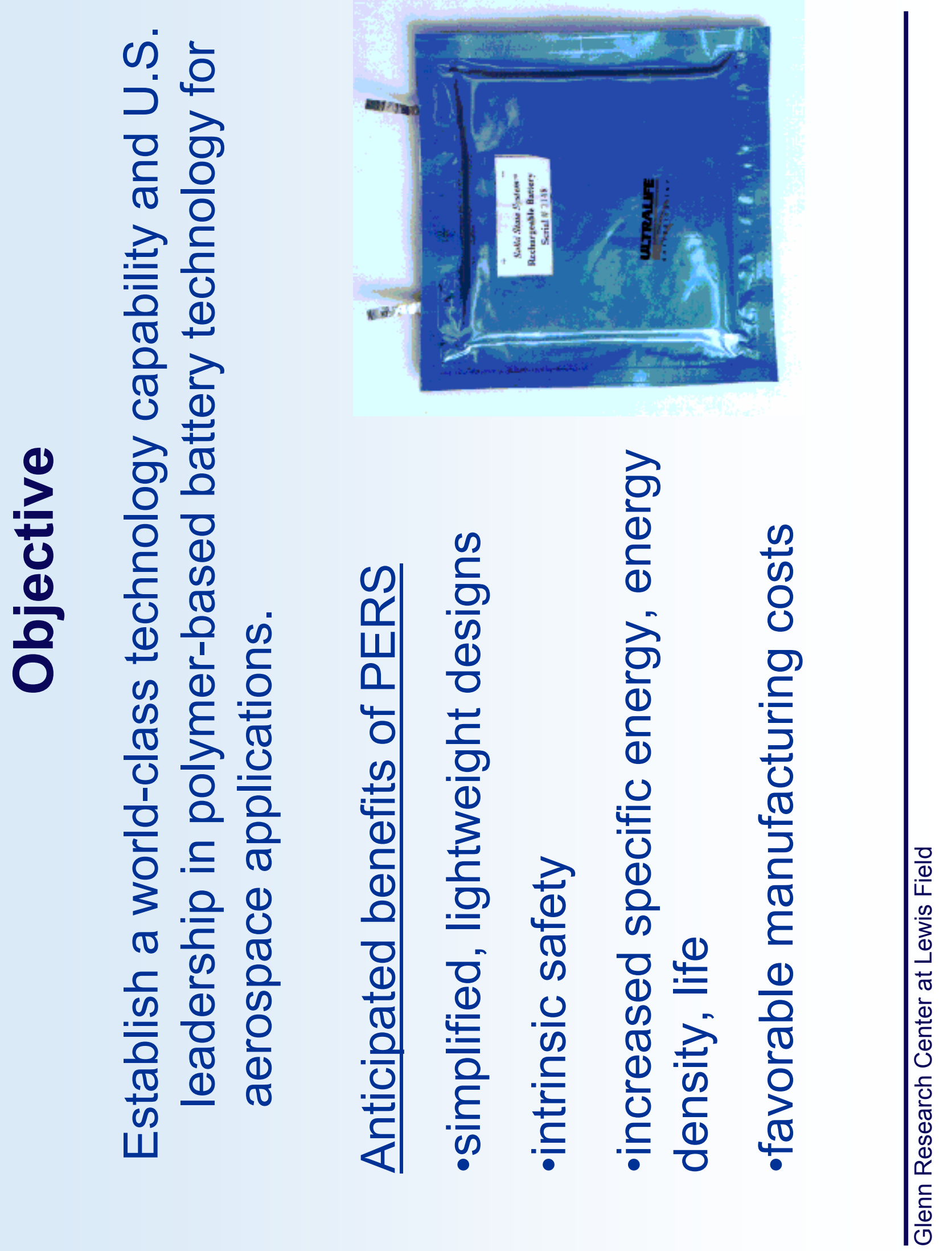


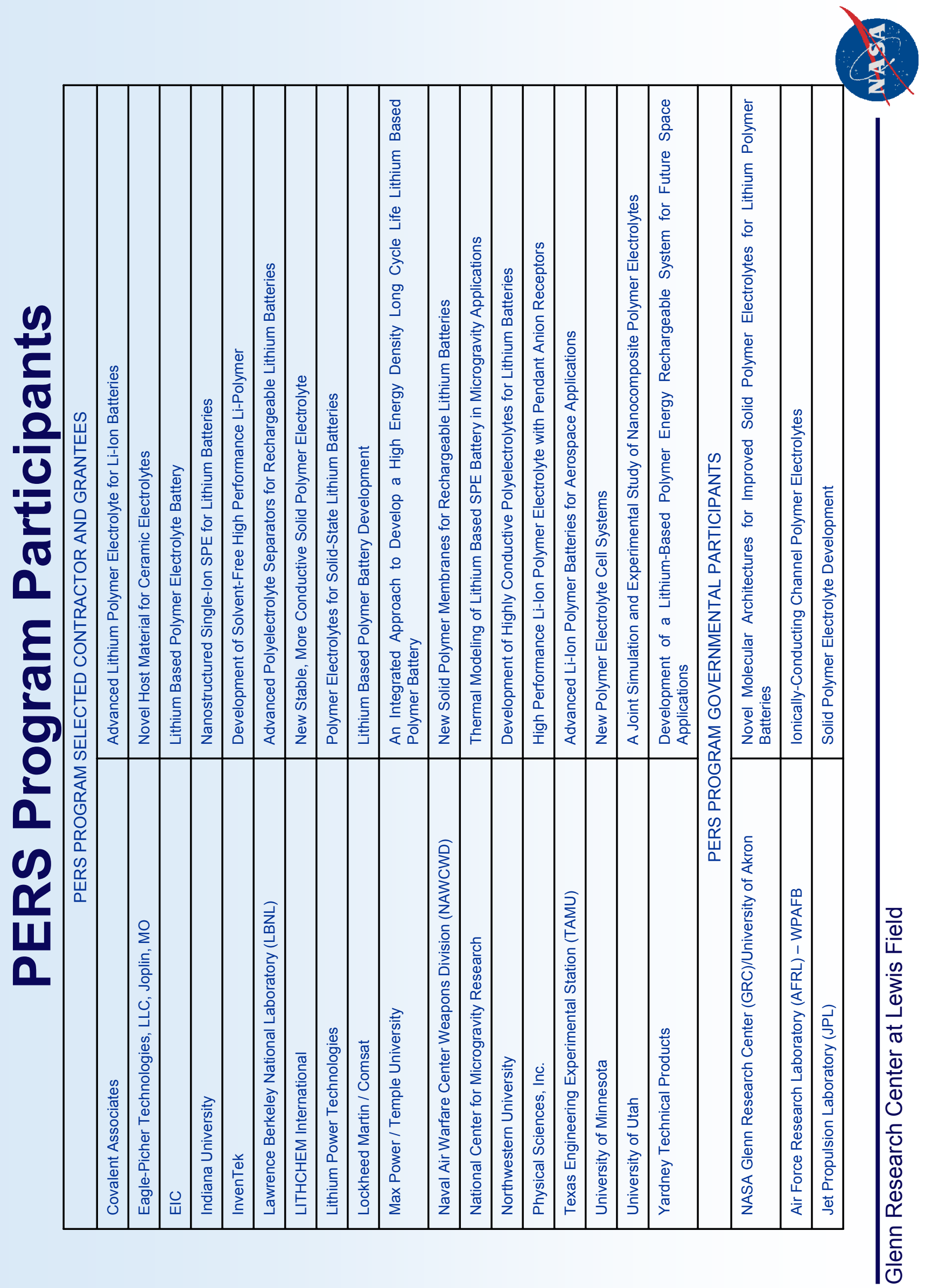




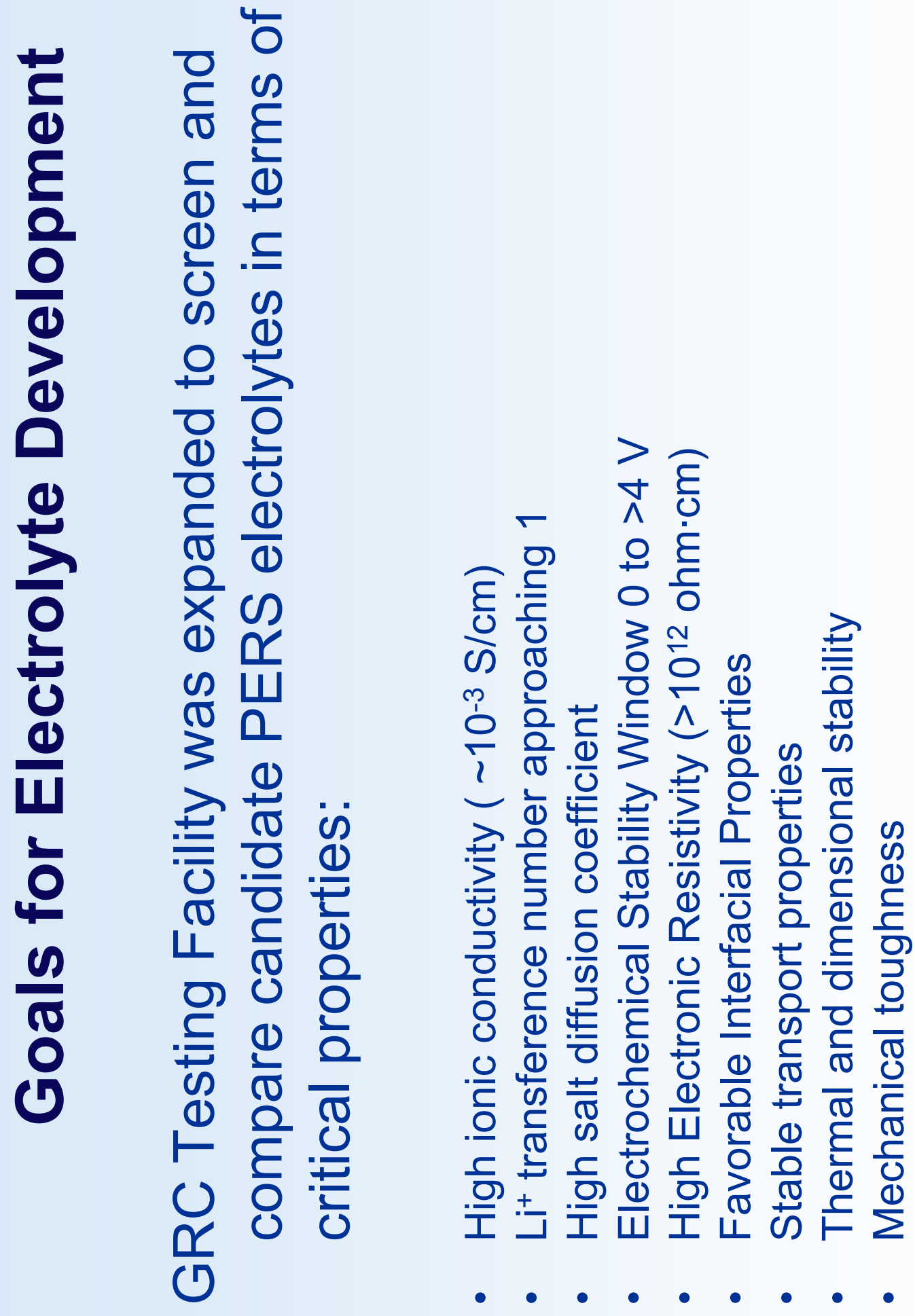




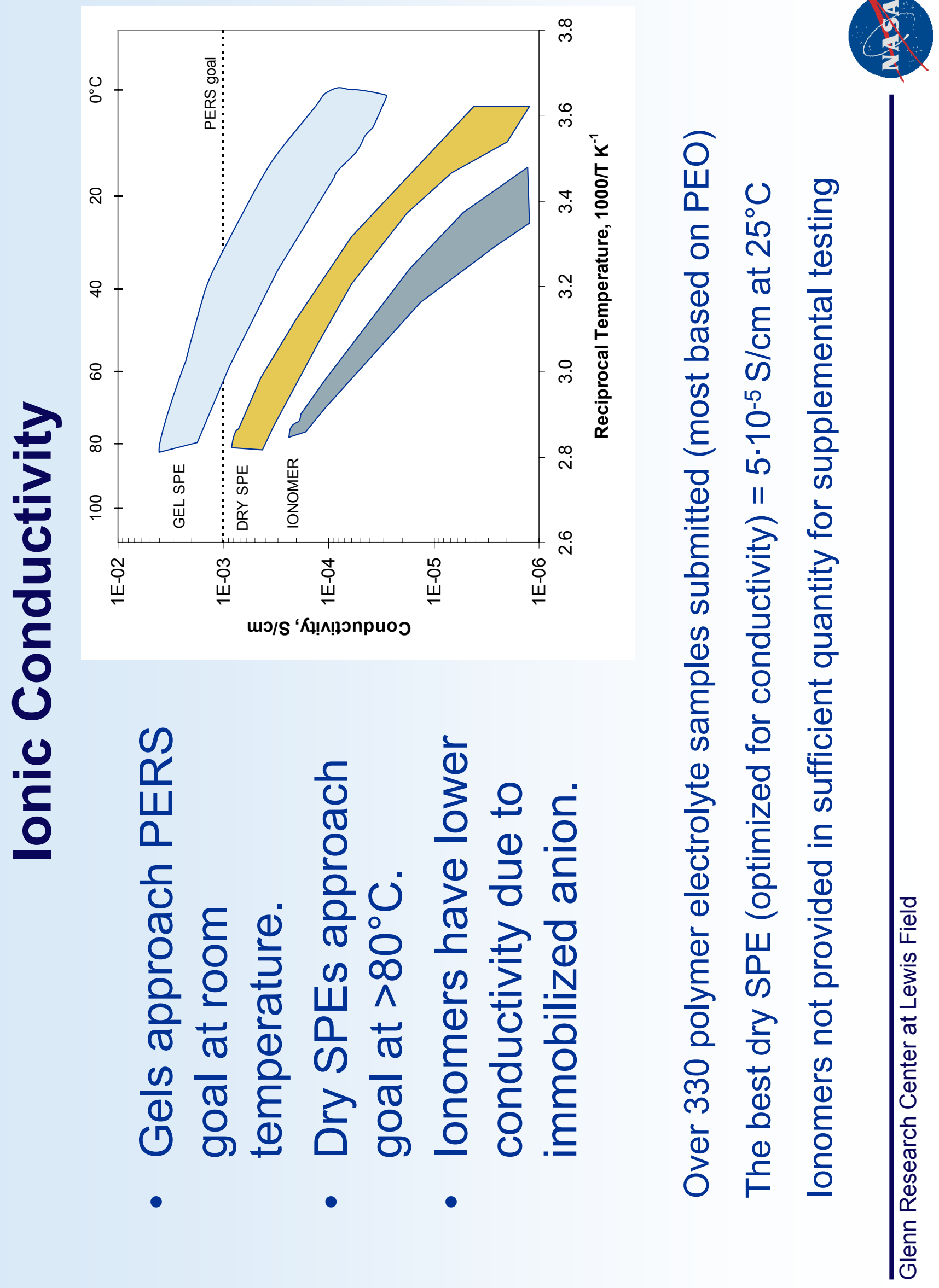




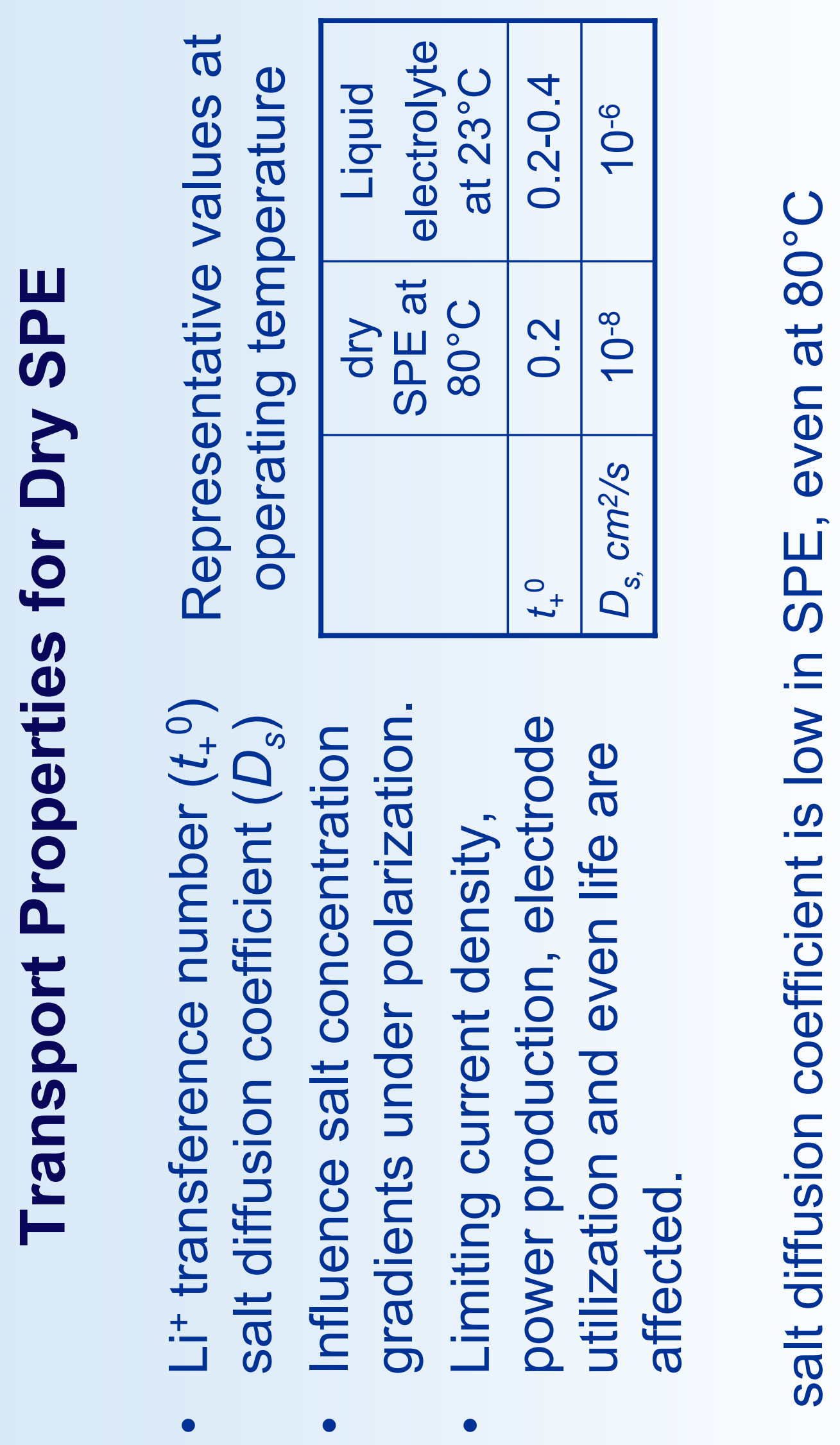



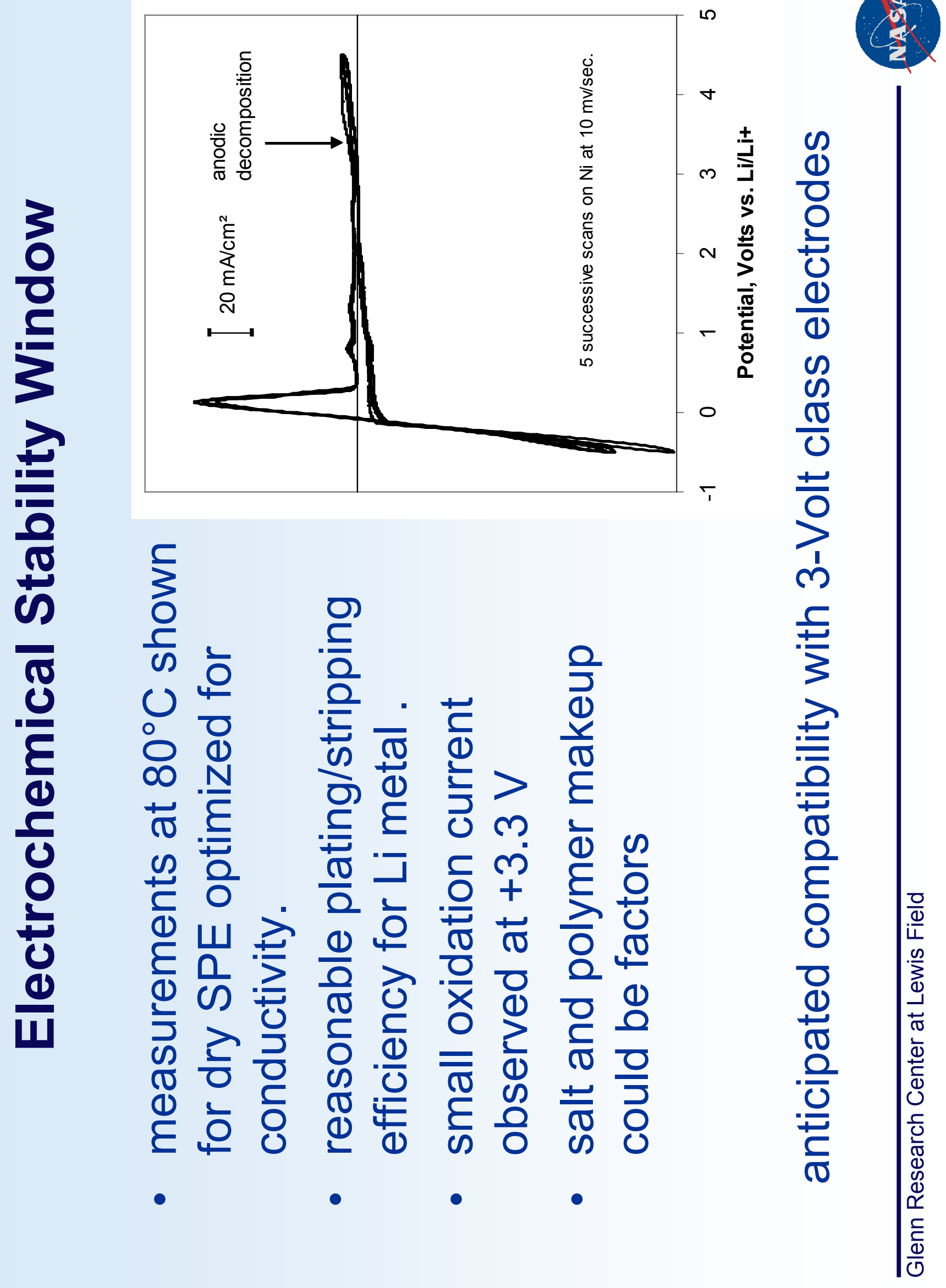


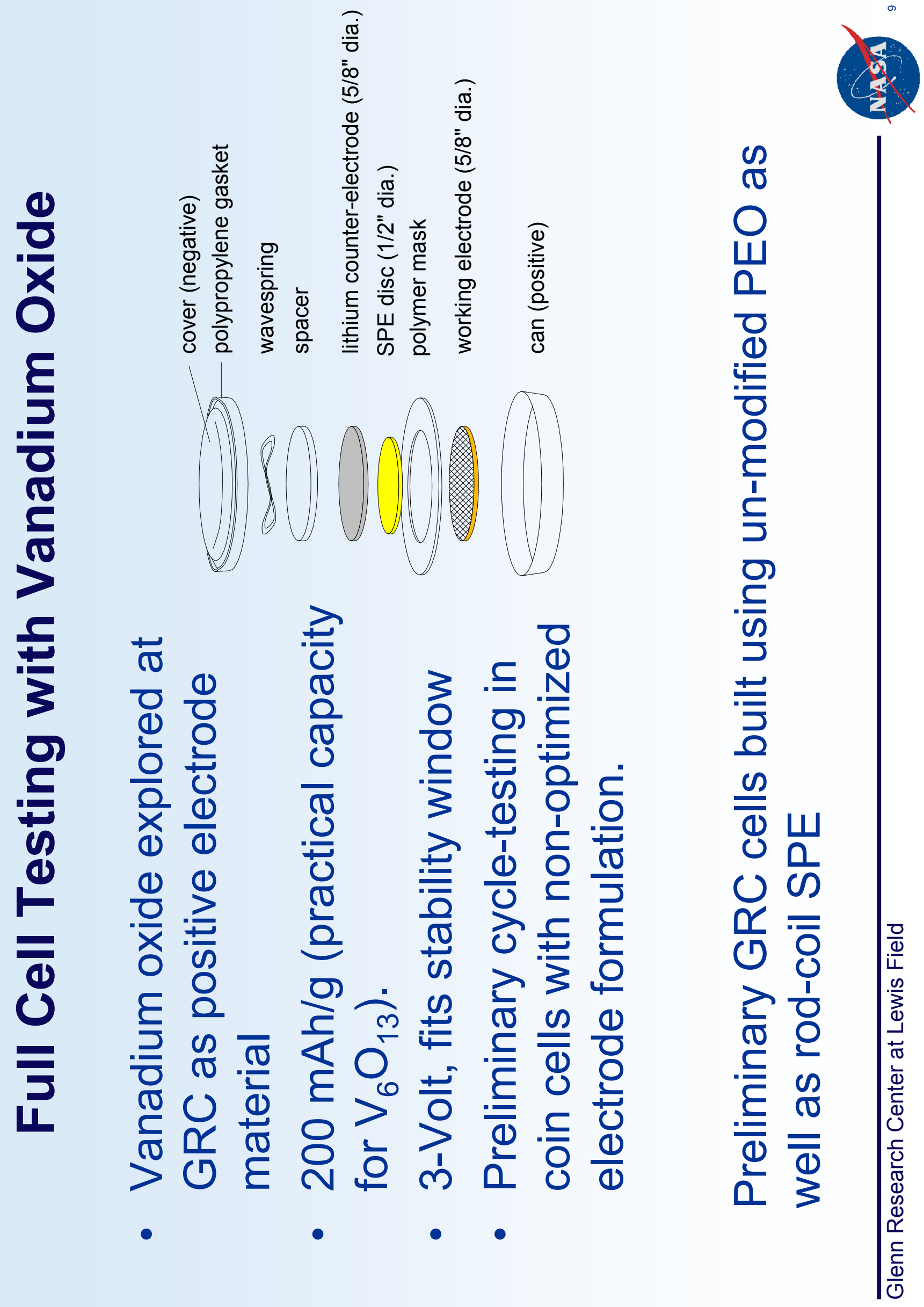




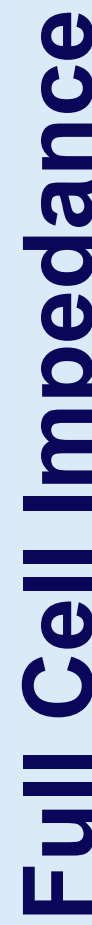

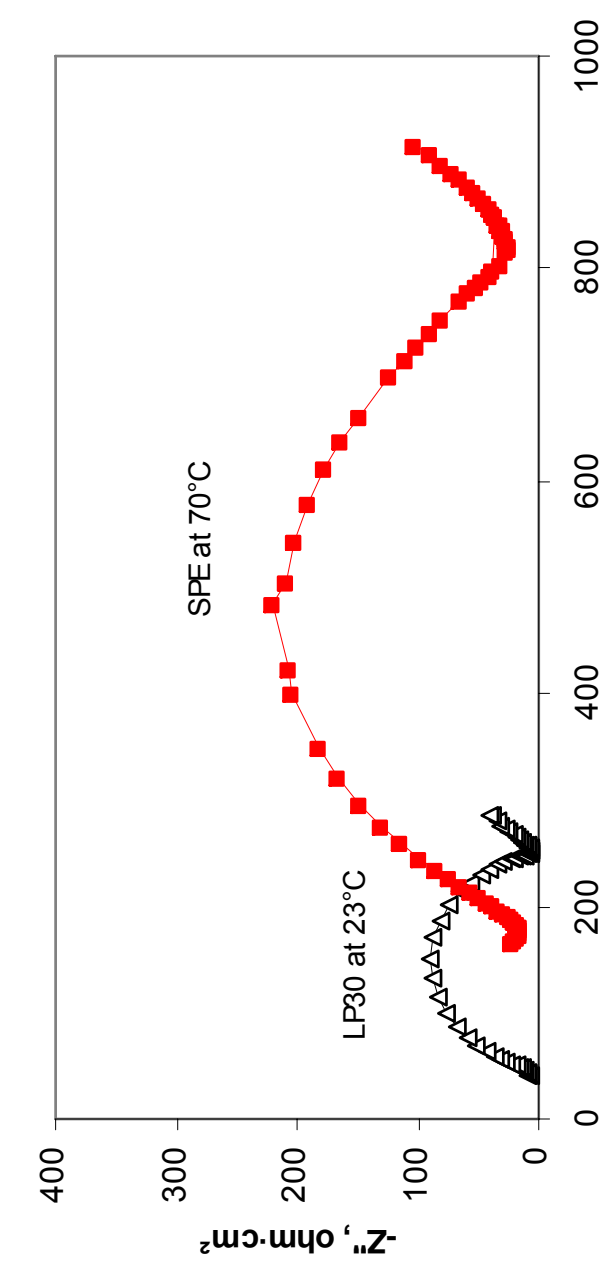

응

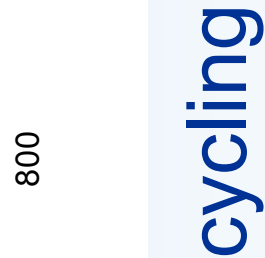

(1)

0

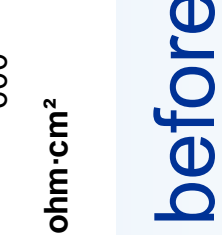

Ni

$\frac{0}{0}$

는

4

(1)

0

0

0

(1)

()

$\sum_{\infty}^{\infty} \frac{E}{E}$

(1) (1)

$\frac{\varepsilon}{\sigma}=$

凹

$+0$

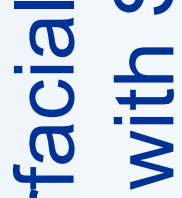

은 윽

응 엉

क ᄃ

4 ర

ำ 

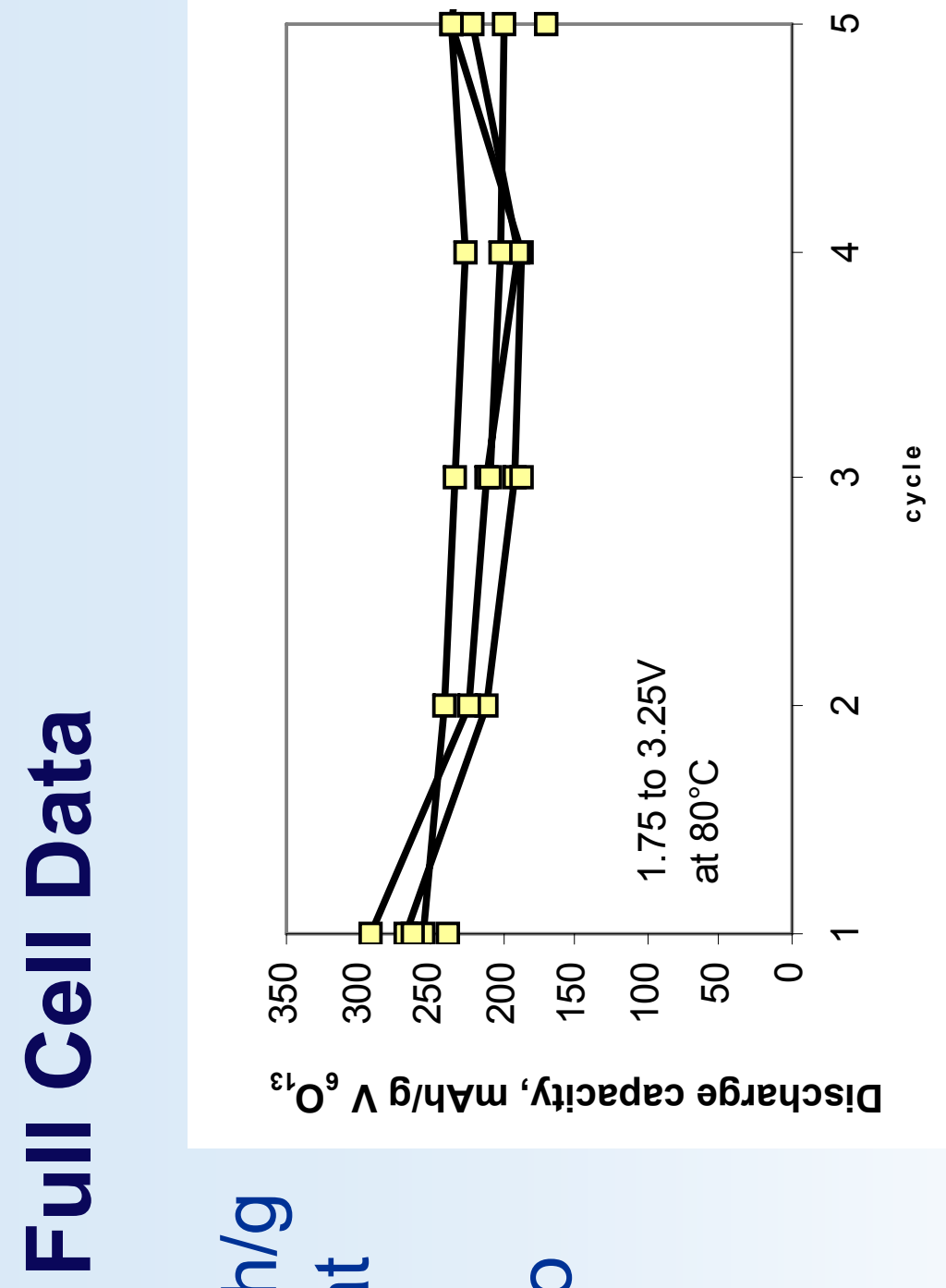

\section{${ }^{\varepsilon l} O^{9} \wedge$ 6/4}

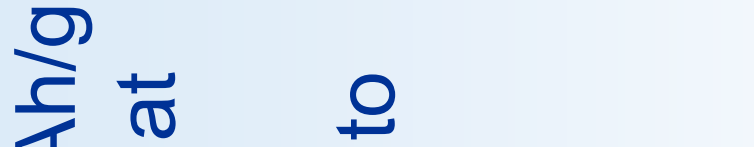

$\frac{\sigma}{1}$

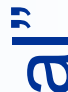

包

$\frac{10}{0}$

0

(1)

$\frac{1}{\sigma}$

ర

$\frac{0}{0}$

E O ह ह $\frac{1}{0}$

$0 \div 0$ ज 0 (1)

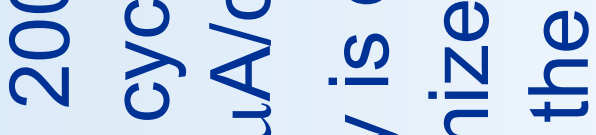

(1)

(1) 0 () 0 르

$\geqslant \pm \infty$ (1)

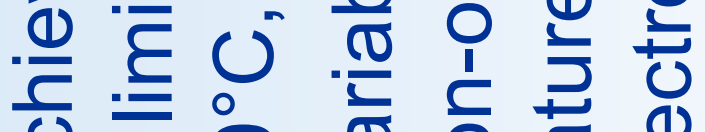

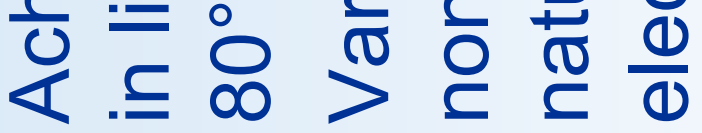

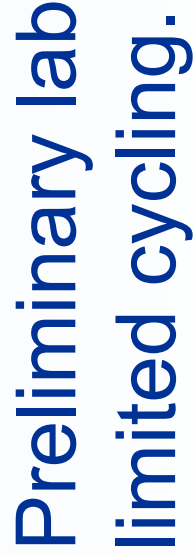




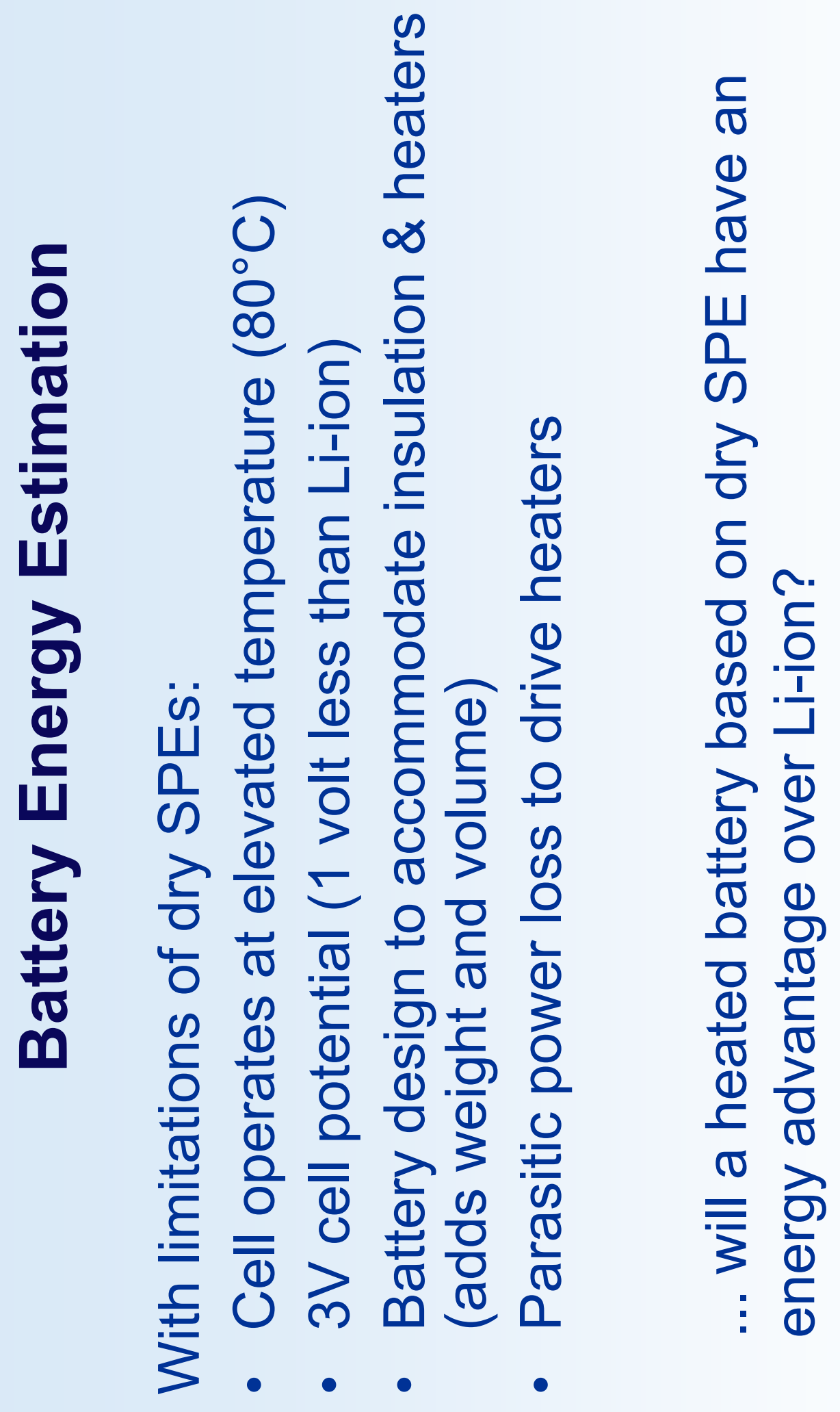




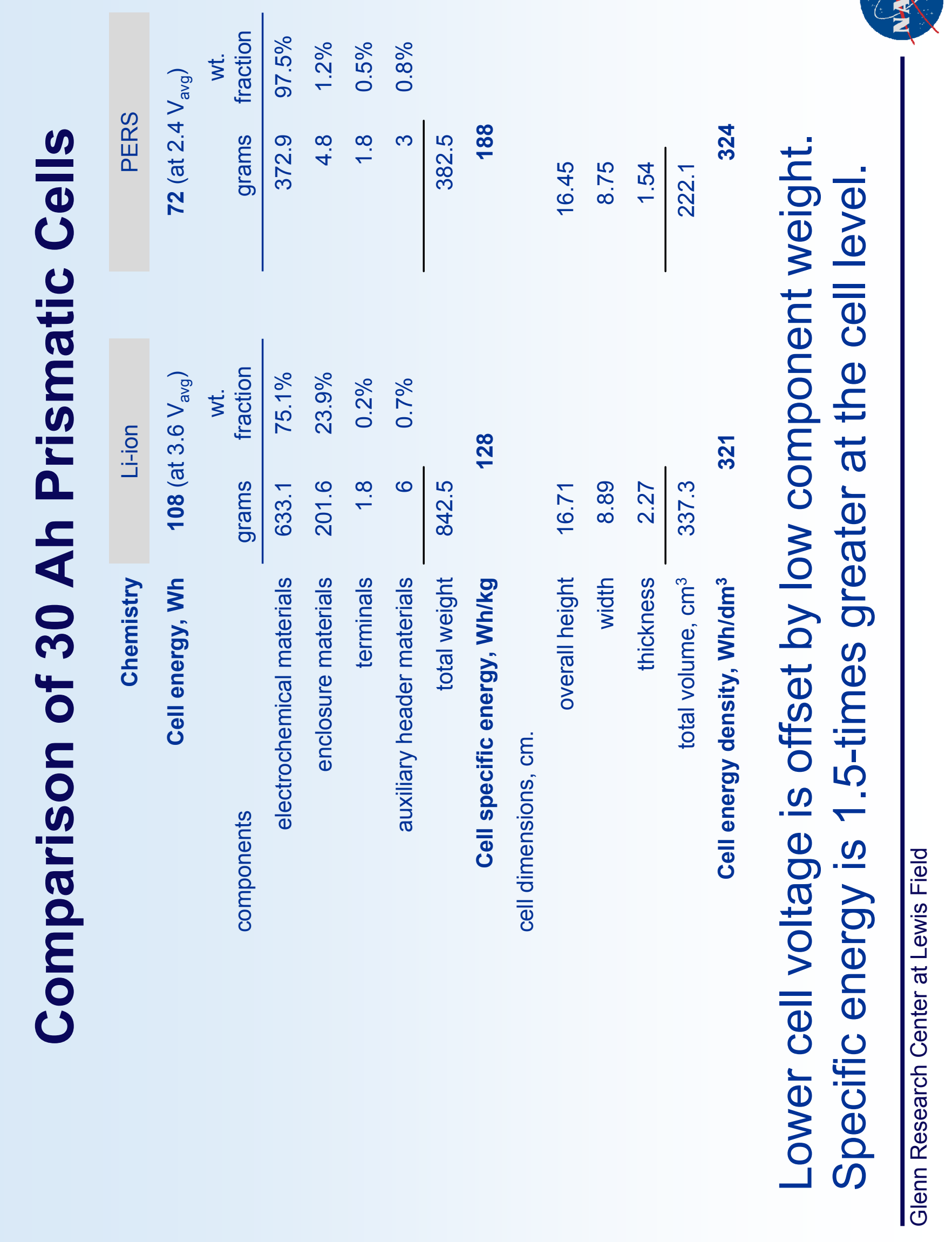




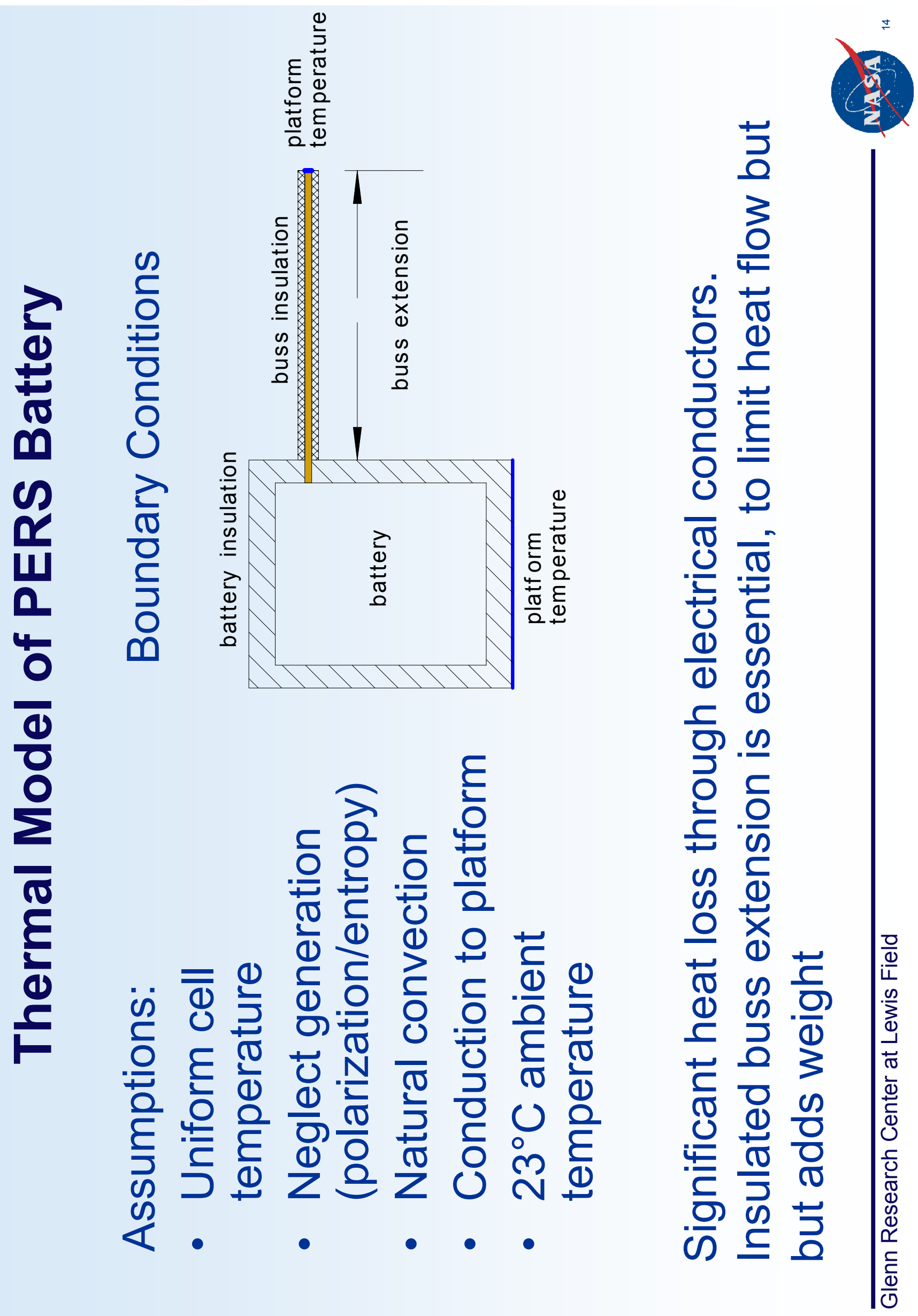




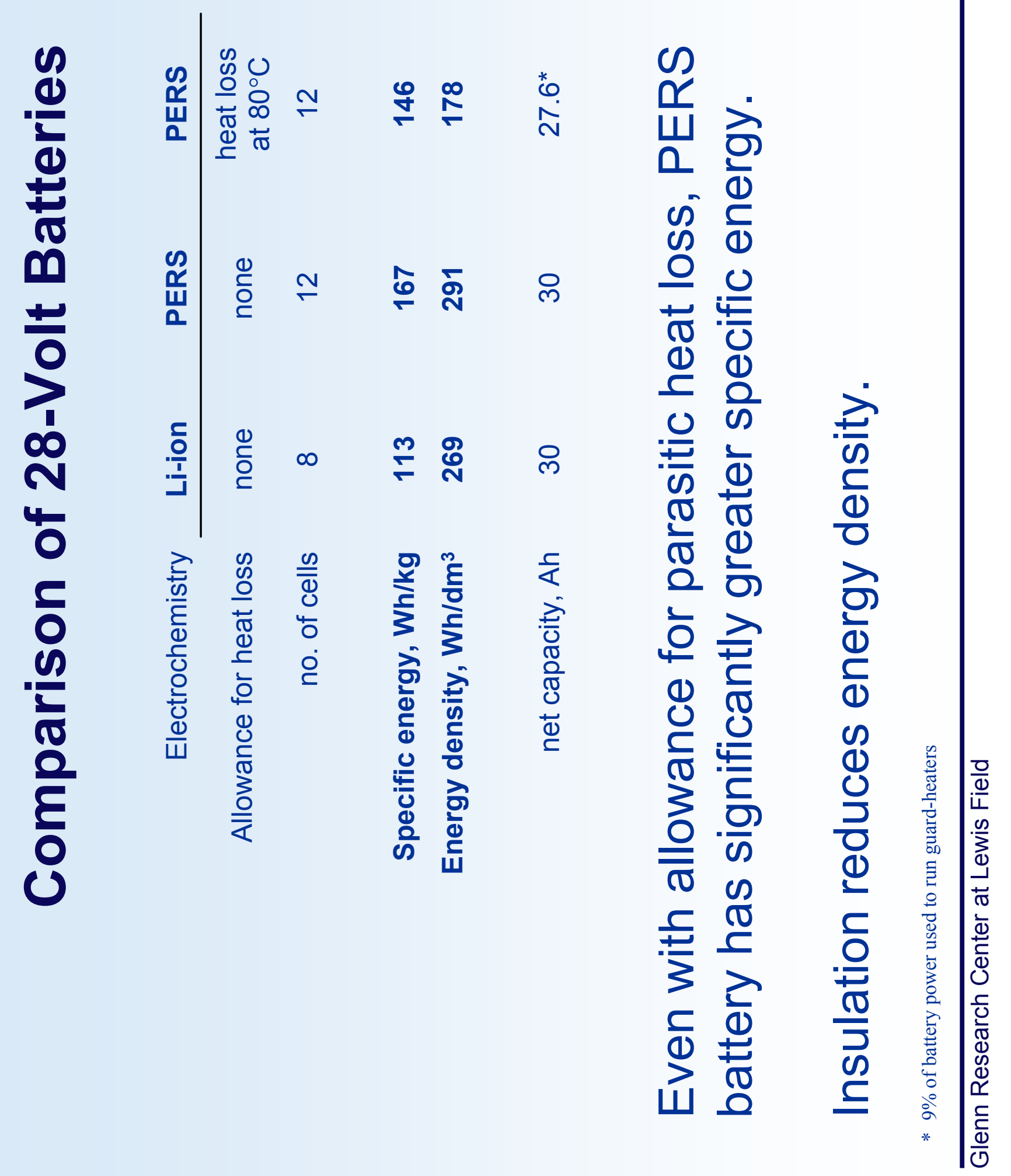


혼

$\frac{1}{0}$

$\frac{1}{0}$
은
$\frac{1}{0}$
$\frac{1}{0}$

정 흥

壱 है

(1) 2

니 듬

口

$0 \quad 0$

음

능 巳

훈

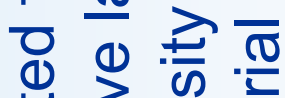

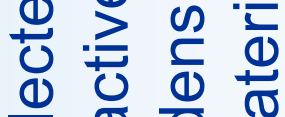

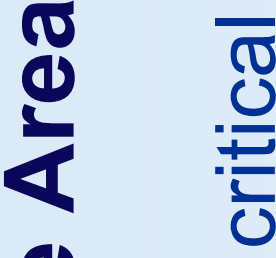

(1)

क ल

ᄃ

$\frac{0}{0}$ 守

क व $\frac{0}{0} \frac{E}{d}$

吾

(1) $\frac{0}{0} 0$

बำ

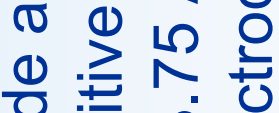

ठ ल

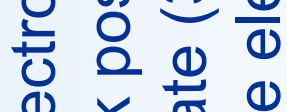

U1

过 는 $\stackrel{0}{ \pm}$

है

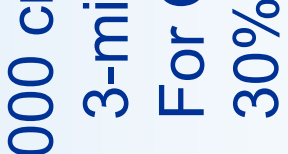

ก.

$m$

4

은

त्व

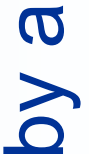

(1)

든

ఫ్ర

(ั)

(1)

$\infty$.

U

ᄃ

$\frac{\mathscr{1}}{\overparen{1}}$

Ð

(1)

过 은

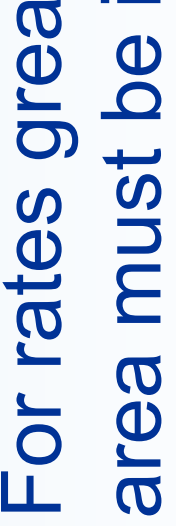



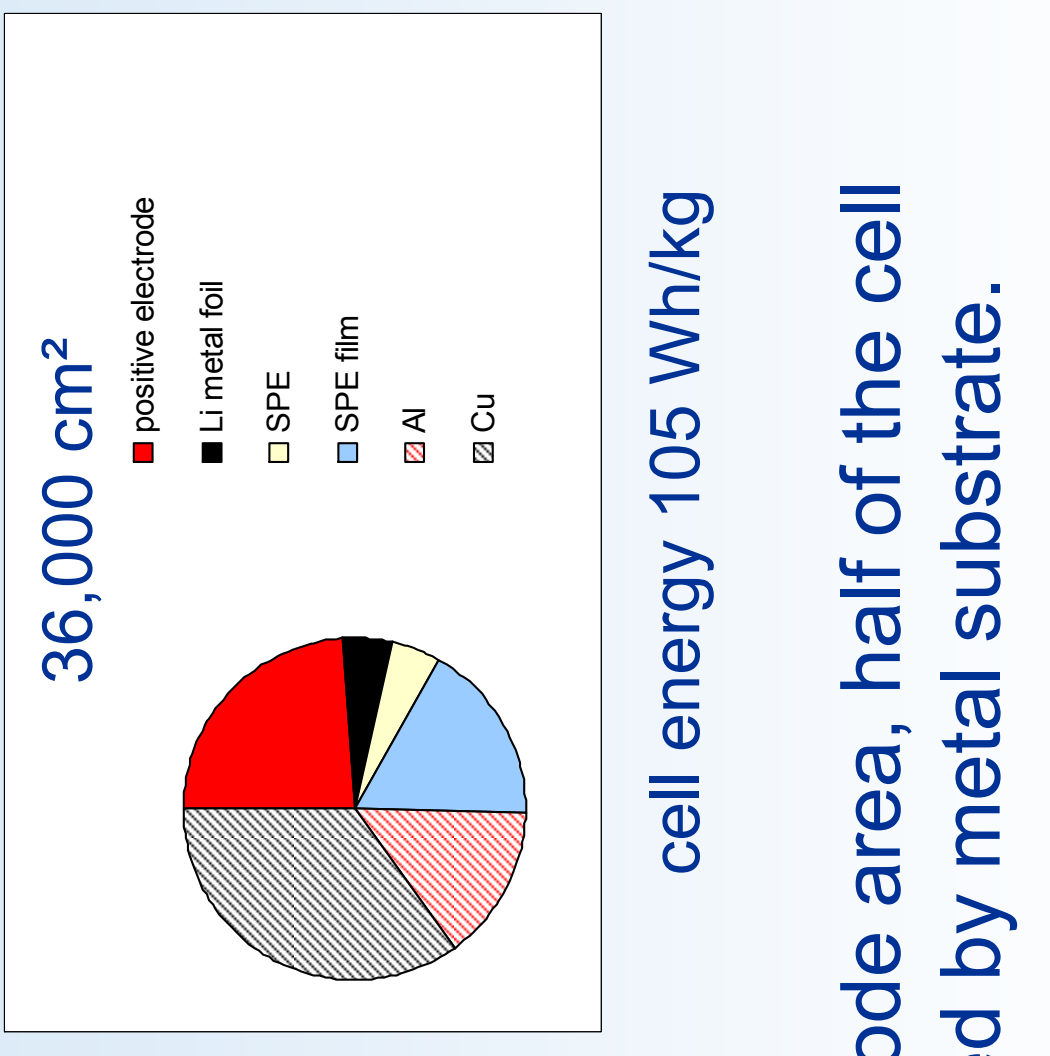

U1

4
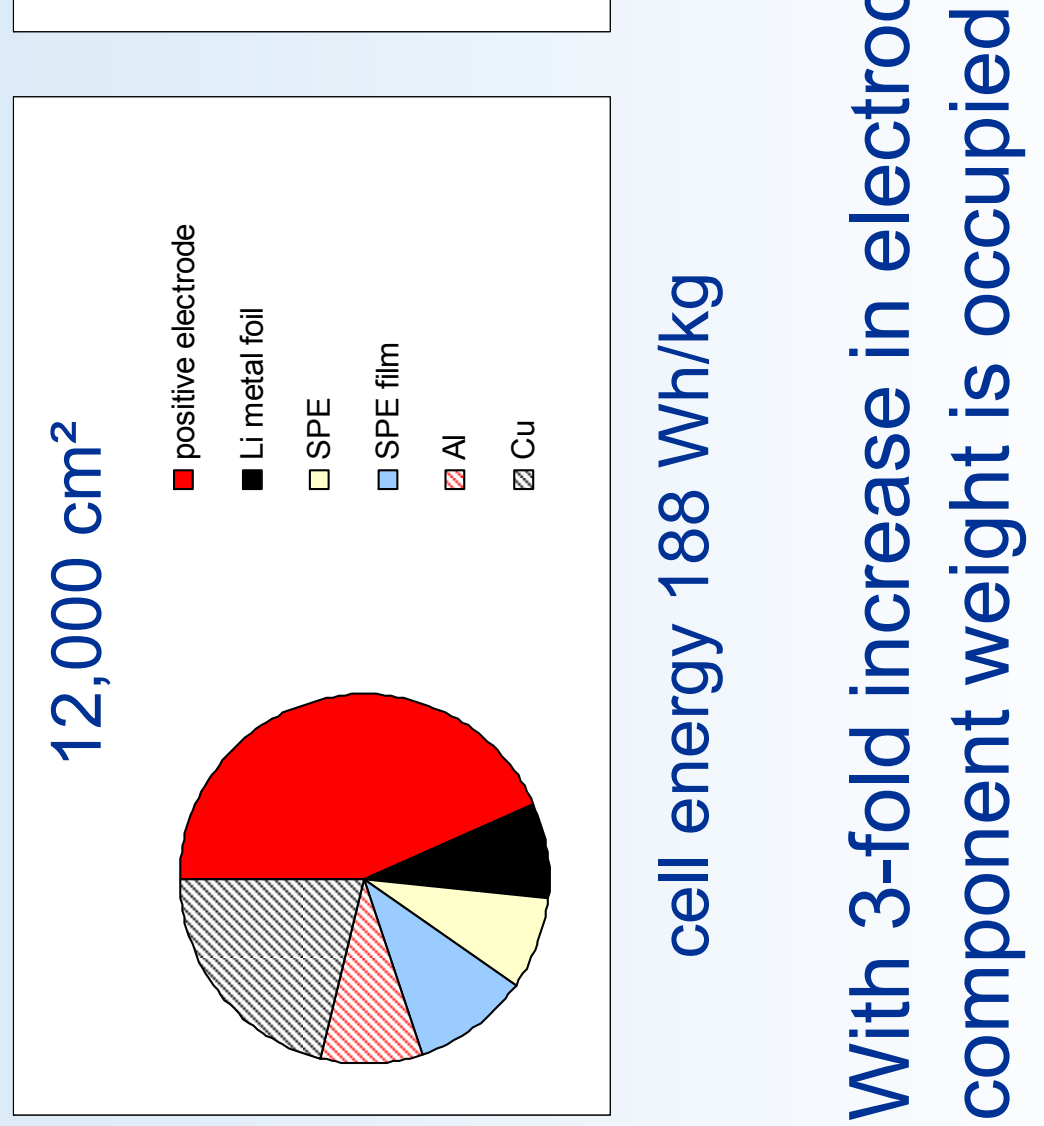

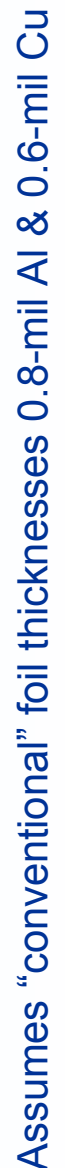




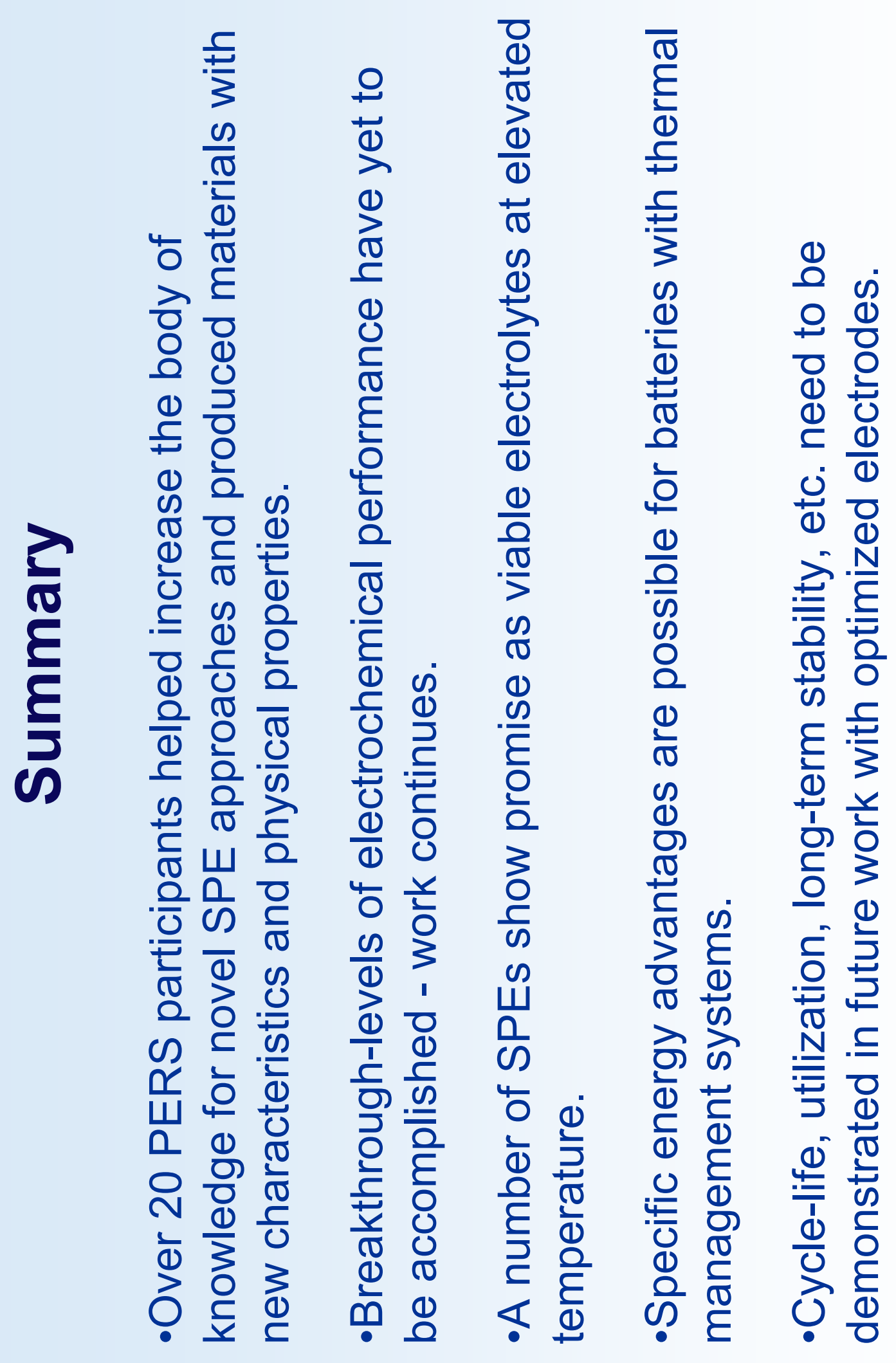




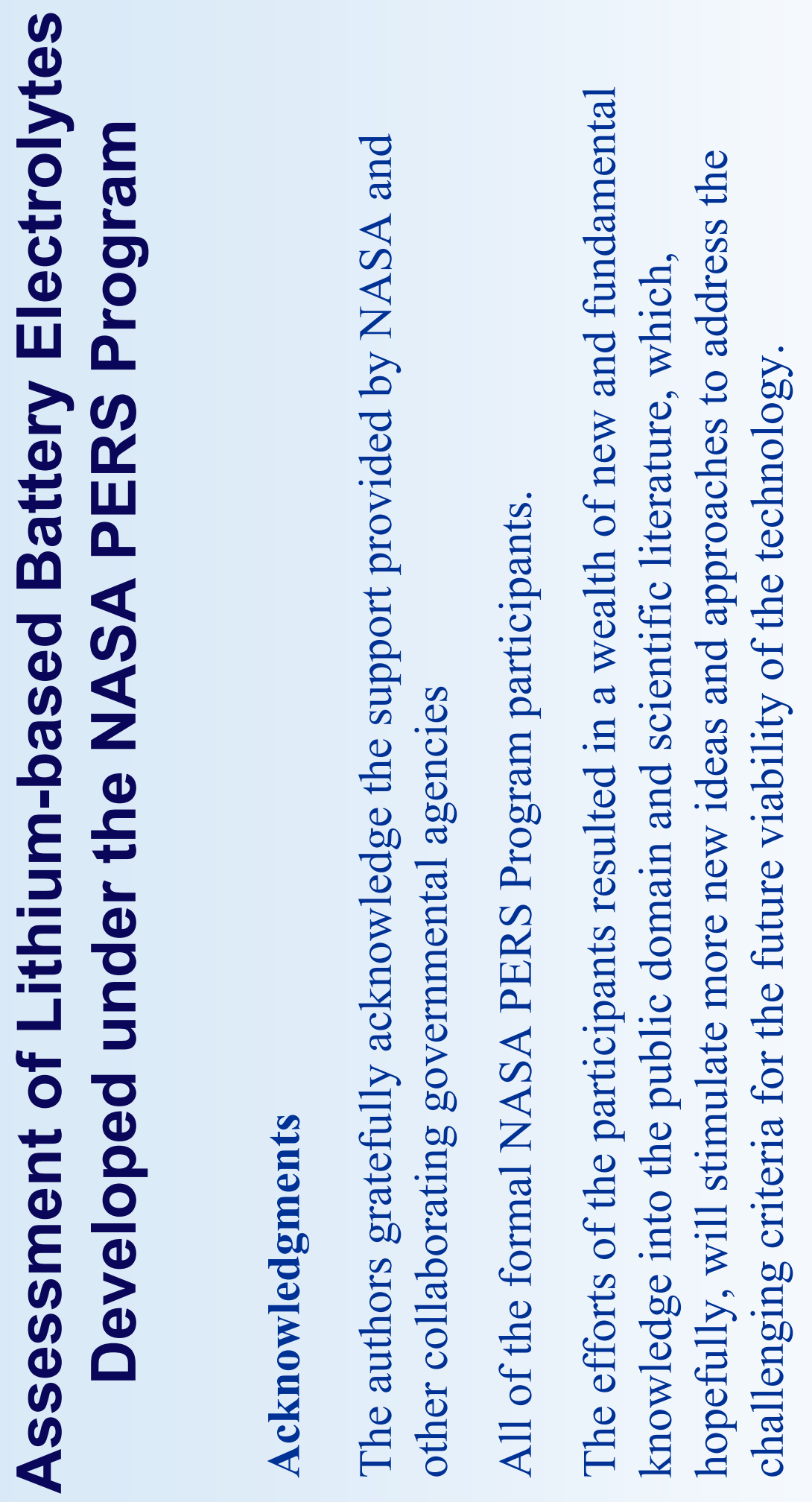

